\title{
Direct cost of peripheral catheterization by nurses
}

\author{
Custo direto da passagem de cateter central de inserção periférica por enfermeiros \\ Costo directo del paso de catéter central de inserción periférica por enfermeros
}

Ana Beatriz Mateus Pires'
ORCID: 0000-0001-6302-522X

Antônio Fernandes Costa Lima' ORCID: 0000-0002-3582-2640

'Universidade de São Paulo, Nursing School. São Paulo, São Paulo, Brazil.

How to cite this article: Pires ABM, Lima AFC. Direct cost of peripheral catheterization by nurses. Rev Bras Enferm [Internet]. 2019;72(1):88-94. DOI: http://dx.doi.org/10.1590/0034-7167-2018-0250

Corresponding Author:

Ana Beatriz Mateus Pires

E-mail: ana.beatriz.mp@hotmail.com

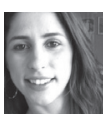

Submission: 04-19-2018

Approval: 07-17-2018

\begin{abstract}
Objective: To measure the average direct cost of peripherally inserted central catheterization performed by nurses in a pediatric and neonatal intensive care unit. Method: A quantitative, exploratory-descriptive, single-case study, whose sample consisted of the non-participant observation of 101 peripherally inserted central catheter procedures. The cost was calculated by multiplying the execution time (timed using a chronometer) spent by nursing professionals, participants in the procedure, by the unit cost of direct labor, added to the cost of materials, drugs, and solutions. Results: The average direct cost of the procedure was US\$326.95 (standard deviation $=$ US\$ 84.47), ranging from US\$ 99.03 to US\$ 530.71, with a median of US\$ 326.17. It was impacted by material costs and the direct labor of the nurses. Conclusion: The measurement of the average direct cost of the peripherally inserted central catheter procedure shed light on the financials of consumed resources, indicating possibilities of intervention aiming to increase efficiency in allocating these resources.
\end{abstract}

Descriptors: Intensive Care Units; Critical Care Nursing; Vascular Access Devices; Costs and Cost Analysis; Direct Service Costs.

\section{RESUMO}

Objetivo: Mensurar o custo direto médio da passagem de cateter central de inserção periférica, por enfermeiros, em uma unidade de terapia intensiva pediátrica e neonatal. Método: Pesquisa quantitativa, exploratório-descritiva, do tipo estudo de caso único, cuja amostra se constituiu da observação não participante de 101 passagens de cateter central de inserção periférica. $O$ custo foi calculado multiplicando-se o tempo (cronometrado) despendido por profissionais de enfermagem, participantes do procedimento, pelo custo unitário da mão de obra direta, somando-se ao custo dos materiais/medicamentos/soluções. Resultados: O custo direto médio do procedimento correspondeu a US\$326.95 (desvio-padrão = US\$ 84.47), variando entre US\$99.03 e US\$530.71, com mediana de US\$326.17; tendo sido impactado pelos custos com material e mão de obra direta dos enfermeiros executantes. Conclusão: A mensuração do custo direto médio da passagem de cateter central de inserção periférica conferiu visibilidade financeira aos insumos consumidos, indicando possibilidades de intervenção visando o incremento da sua eficiência alocativa.

Descritores: Unidades de Terapia Intensiva; Enfermagem de Cuidados Críticos; Dispositivos de Acesso Vascular; Custos e Análise de Custo; Custos Diretos de Serviços.

\section{RESUMEN}

Objetivo: Medir el costo directo promedio del paso de catéter central de inserción periférica por enfermeras en una unidad de cuidados intensivos pediátrica y neonatal. Método: Investigación cuantitativa, exploratoria-descriptiva, del tipo estudio de caso único, cuya muestra se constituyó de la observación no participante de 101 pasos de catéter central de inserción periférica. El costo se calculó multiplicando el tiempo (cronometrado) de los profesionales de enfermería, participantes en el procedimiento, por el costo unitario de mano de obra directa, sumándose al costo de materiales/ medicamentos/soluciones. Resultados: El costo directo medio del procedimiento correspondió a US\$326,95 (desviación estándar $=$ US\$ 84,47), variando entre US\$ 99,03 y US\$ 530,71 , con mediana de US\$ 326,17 , habiendo sido impactados por los costos con material y mano de obra directa de los enfermeros ejecutantes. Conclusión: La medición del costo directo medio del paso del catéter central de inserción periférica confirió visibilidad financiera a los insumos consumidos, indicando posibilidades de intervención pretendiendo incrementar su eficiencia alocativa.

Descriptores: Unidades de Cuidados Intensivos; Enfermería de Cuidados Críticos; Dispositivos de Acceso Vascular; Costos y Análisis de Costo; Costos Directos de Servicios. 


\section{INTRODUCTION}

Critically ill patients admitted to intensive care units (ICUs) often require central venous access for hemodynamic monitoring, drug administration, hydration and volume replacement. Among medical devices eligible to meet these needs, the peripherally inserted central catheter (PICC) has been progressively gaining space in Brazilian hospital organizations ${ }^{(1)}$.

The preferential indication of PICC to enable long intravenous therapy has increased due to the fact that it ensures less traumatic insertions, greater availability of venipuncture sites, and less chance of accidents (pneumo and hemothorax) or contamination during its implantation ${ }^{(2)}$.

Nurses play an important role in the insertion, maintenance and removal of PICC, especially in neonatal intensive care units (NICUs), considering that the infusion of hyperosmolar, irritant or vesicant solutions requires safe and efficient central venous access $^{(3)}$. In Brazil, the nurse is required to have specific technicalscientific qualification in order to execute the PICC. The procedure demands specialized human resources, materials, drugs and solutions whose consumption generates costs that need to be determined and properly managed.

A research conducted in a teaching hospital with extra capacity, identifying the consumption and costs of materials for care service in intensive and semi-intensive pediatric units, showed that among materials in the 'A' classification of the $A B C$ curve the PICC had the greatest representativeness, amounting to a cost of $R \$ 16,210.00$ or $8.5 \%$ of the total value spent by the hospital in the studied period. The study found that the use of this material had strict administrative control, justified by its impact on hospital finances ${ }^{(4)}$.

Recently, several studies ${ }^{(4-13)}$ have demonstrated the importance of material resource costs in the provision of health services. However, in spite of recurrent searches in the literature, we found no recent international or national studies investigating the costs associated with the PICC procedure while considering not only material resources, but also human resources, evidencing a knowledge gap in this subject.

It should be emphasized that knowledge about the costs incurred in medical assistance allows a detailed analysis of the financial situation of hospital organizations, subsidizes the decision-making process, and promotes the adoption of corrective actions in different management areas. From this perspective, the provision of effective, efficient and high-quality assistance, together with the optimization of scarce resources, presents itself as a challenge, especially to public health management ${ }^{(13-14)}$. In complex health care units, nurses can contribute to shed light on expenditures, as long as they are aware of their patient's profile, the type of care provided, and the necessary therapeutic approach $^{(4)}$. In view of the above, this study was carried out to generate knowledge that helps establish better efficacy in the allocation of resources necessary for PICC procedures.

\section{OBJECTIVE}

To measure the average direct cost (ADC) of PICC procedures performed by nurses in a pediatric and neonatal intensive care unit (PNICU).

\section{METHOD}

\section{Ethical aspects}

The project met all directives and regulatory standards for research involving human subjects, and was approved by the Ethics and Research Committee of the teaching hospital.

\section{Design, location of the study and study period}

This is a quantitative, exploratory-descriptive, single-case study ${ }^{(15)}$, carried out in the PNICU of a public teaching hospital from January to October 2016.

At the time of the study, the PNICU had a total of 13 active beds, nine in the pediatric area and four in the neonatal area. The staff consisted of one head nurse, 14 nursing assistants, 26 technicians and two nursing assistants. The average number of staff per shift was two nurses and five technicians. The Unit is one of the fields of practice for nursing residents of the "Residency Program in Nursing for Child and Adolescent Health" of the School of Nursing of the University of São Paulo. In the execution of PICC procedures, preference is given to qualified resident nurses, initially accompanied by a preceptor nurse. Later, under the supervision of the preceptor, the execution of the procedure becomes a strategy for professional improvement and qualification.

\section{Population or sample; inclusion and exclusion criteria}

The calculated sample (95\% confidence interval and 10\% statistical error tolerance) amounted to a minimum of 100 nonparticipant observations of the PICC procedure. All procedures performed by nurses were included, while procedures performed by physicians were excluded.

\section{Study protocol}

Data collection took place in the period from January to October 2016, after signing of an Informed Consent Form by all the PNICU's nurses and nursing residents qualified in the execution of the PICC, together with nurses and technicians/auxiliaries who provided support for the procedures.

An instrument was created to record the time it took for the nursing professionals to execute the PICC (timed using a chronometer), as well as to document the consumption of materials, medications and solutions. This instrument was structured according to the procedure's sequential phases: pre-insertion of the catheter (evaluation of the venous network and measurement of the catheter; providing guidance to the patient and companion; mobilization of materials; preparation and administration of sedation/analgesia; initial positioning of the patient; initial skin antisepsis; scrubbing, gowning and gloving; opening of surgical drapes and preparation of materials; final skin antisepsis), insertion of the catheter (venipuncture, insertion and progression of the device, and radiological confirmation), and post-insertion of the catheter (dressing of the device's insertion site). It also contained an input field to record the difficulties encountered by the nurse responsible for execution of the PICC procedure, whether the procedure was successfully completed or not. 
For all observations, the execution time was counted from the moment the nurse practitioner began evaluating the venous network and measuring the catheter until the dressing of the insertion site. Hand scrubbing, questions asked to the medical staff about sedation for the procedure, positioning of the patient to perform radiographs, evaluation of these by other nurses, and mobilization of materials from other care units were also timed.

The study's conceptual basis was direct cost, defined as any cost that can be clearly identified and quantified ${ }^{(16)}$. In studies of this nature, the objective measure of consumption is comprised of the employed materials, drugs and solutions, as well as direct labor ${ }^{(17)}$.

Direct labor refers to personnel working directly on the product, as long as it is possible to measure time spent and identify who performed the work, with no indirect appropriation or apportionment. It consists of monthly salaries, social security charges, holiday provisions and 13th salary ${ }^{(16)}$. Thus, the direct labor of the PNICU's nursing professionals was calculated from the average salaries (salaries, benefits, bonuses and social security charges), per professional category, in the data collection period. These data were provided by the Department of Human Resources of the teaching hospital.

The unit costs of materials, medicines and solutions were provided by the institution's Purchasing, Pharmacy and Warehousing Sector, consisting of the amount paid for the replacement of the last three acquisitions or the value of last year's acquisition.

The cost was calculated by multiplying the execution time (timed using a chronometer) spent by nursing professionals who participated in the procedure by the unit cost of direct labor, added to the cost of materials, drugs, and solutions.

As the execution of a procedure requires the consumption of different quantities of materials, it is possible to establish the value of its average direct cost $\left[C\left(P_{i}\right)\right]$ from the average direct cost of materials $\overline{C\left(P_{i}\right)_{\text {mat }}}$; solutions $\left[\overline{C\left(P_{i}\right)_{\text {sol }}}\right]$ and labor $\left[\overline{C\left(P_{i}\right)_{\text {mob }}}\right]^{(18)}$ : $\overline{C\left(P_{i}\right)}=\overline{C\left(P_{i}\right)_{\text {mat }}}+\overline{C\left(P_{i}\right)_{\text {sol }}}+\overline{C\left(P_{i}\right)_{\text {mob }}}$ (equation 1 ).

$\left[\overline{\left.C\left(P_{i}\right)_{\text {mat }}\right]}\right.$ is obtained from the sum of the average costs $[\overline{\mathrm{Cm}}]$ of each material [k] used in the procedure ${ }^{(18)}: \overline{C\left(P_{i}\right)_{\text {mat }}}=\sum_{k=1}^{n} \overline{C m_{k}}$ (equation 2).

The $\overline{C\left(P_{i}\right)_{\text {mat }}}$ of each material can be obtained from the product of the average quantity $\left[\overline{q m_{k}}\right]$ by its average unit price $\left[\overline{P m u_{k}}\right]$ : $\overline{C m_{k}}=\overline{q m_{k}} \cdot \overline{P m u_{k}}$ (equation 3).

By substituting equation (3) into equation (2), the following equation is obtained: $\overline{C\left(P_{i}\right)_{m a t}}=\sum_{k=1}^{n} \overline{\overline{q m_{k}}} \cdot \overline{P m u_{k}}$ (equation 4).

The $\overline{C\left(P_{i}\right)_{\text {sol }}}$ is obtained from the sum of the average costs $\left[\overline{C s_{k}}\right]$ of each solution and drug consumed ${ }^{(18)}: \overline{C\left(P_{i}\right)_{s o l}}=\sum_{k=1}^{n}$ $\overline{C s_{k}}$ (equation 5).

Thus, the $\overline{C\left(P_{i}\right)_{\text {sol }}}$ is obtained from the product of the average amount of solution/drug $\left[\overline{q s_{k}}\right]$ by its average unit price $\left[\overline{P s u_{k}}\right]$ : $\overline{C s_{k}}=\overline{q s_{k}} \cdot \overline{P s u_{k}}$ (equation 6).

Substituting equation (6) into equation (5) leads to (the more detailed) equation: $\overline{C\left(P_{i}\right)_{s o l}}=\sum_{k=1}^{n}\left(\overline{q s_{k}} \cdot \overline{P s u_{k}}\right)$ (equation 7).

$\overline{C\left(P_{i}\right)_{m o b}}$ can be obtained from the sum of the average costs of each professional category (nurses and nursing technicians) $\left[\overline{C h_{c}}\right]$ participating in the procedure ${ }^{(18)}: \overline{C\left(P_{i}\right)_{m o b}}=\sum_{c=1}^{n} \overline{C h_{c}}$ (equation 8).

The $\overline{C\left(P_{i}\right)_{m o b}}$ was obtained from the product of the average time spent by the category $[c]$ in the procedure $\left[\overline{t_{c}}\right]$ by the average unit cost of labor $\left[\overline{S u_{c}}\right]: \overline{C h_{c}}=\overline{t_{c}} \cdot \overline{S u_{c}}$ (equation 9).

Substituting equation (9) in equation (8) yields the following equation: $\overline{C\left(P_{i}\right)_{m o b}}=\sum_{k=1}^{n}\left(\overline{t_{c}} \cdot \overline{S u_{c}}\right)($ equation 10$)$.
Finally, by substituting equations (4), (7) and (10) into equation (1), we obtain equation $11^{(18)}: \overline{C\left(P_{i}\right)}=\sum_{k=1}^{n}\left(\overline{q_{k}} \cdot \overline{P u_{k}}\right)$ $+\sum_{k=1}^{n}\left(\overline{q s_{k}} \cdot \overline{P s u_{k}}\right)+\sum_{c=1}^{n}\left(\overline{t_{c}} \cdot \overline{S u_{c}}\right)(11)$.

The following intervening variables were defined in order to determine $\overline{C\left(P_{i}\right)}$ : average amount of materials $\overline{q m_{k}}$ []; average unit price of each material $\left[\overline{\mathrm{Pmu_{k }}}\right]$; average number of solutions or drugs $\left[\overline{q s_{k}}\right]$; average unit price of each solution or medicinal product $\left[\overline{P s u_{k}}\right]$; average time of dedication of each professional category $\left[\overline{t_{c}}\right]$; average gross salary of each professional category $\left[\overline{s u_{c}}\right]^{(18)}$.

\section{Analysis of results and statistics}

The data was input into spreadsheets and the variables "nurse costs," "technician/assistant costs," "nursing team ADC," "cost of materials," "cost of solutions," "cost of drugs," and "procedure ADC" were presented as minimum and maximum values, means, standard deviations, medians, and modes. In order to calculate the ADC of the PICC procedure, the Brazilian currency (R\$) was converted to American dollars (US\$) at the rate of US\$ 0.31/R\$, based on the Brazilian Central Bank's August 31, 2016 quotation.

\section{RESULTS}

During the data collection period, 14 nurses and four nursing residents were observed performing the PICC procedure. Mean age was 36.78 years $(S D=9.00)$; mean time of nursing training was 13.44 years $(S D=8.87)$; mean time of service in the PICU was 9.46 years $(S D=7.87)$, and mean experience with the execution of the PICC procedure was 6.77 years $(S D=5.01)$.

Seventy-three patients (100\%) allowed for the non-participant observations of 101 PICC procedures. In the neonatology area, 22 patients (91.67\%) were newborns and two (8.33\%) were infants; in the pediatric area, 35 (71.43\%) were infants, six (12.24\%) were preschoolers and eight (16.33\%) were school children. All presented some medical diagnostic hypothesis related to respiratory conditions. Otherwise, they had sepsis (47 patients) and prematurity (15 patients). Fifty-three patients (72.60\%) underwent only one puncture for insertion of the device, while 20 patients were submitted to more than one, the majority (15-75\%) underwent two venous punctures.

Among PICC procedures, 70 (69.31\%) were successfully completed, with the device being inserted and kept in the patient's body, and 31 were unsuccessful (30.69\%), that is, despite insertion attempts, permanence of the device was not feasible. The majority of punctures (57.75\%) occurred in the upper limbs, while $19.31 \%$ were in the lower limbs, $16.50 \%$ in the right and left jugular veins, and $6.44 \%$ in the cephalic regions.

An average of two professionals (nurse practitioner and support nursing professional) participated in the "insertion of the catheter" phase, with $S D=1.00$, median $=2$, and mode $=1$ professional (nurse practitioner). The nurse practitioners described difficulties with the passage of the device in $55.45 \%$ of the PICC procedures, and with the venipuncture in $48.51 \%$. The following main difficulties stood out: patient agitation (27 reports), lack of visibility of blood vessels (26 reports), capillary fragility (14 reports), additional venipunctures (11 reports) and inferior quality of the material (10 reports). 
Table 1 - Distribution of successful Peripherally inserted central catheter procedure observations, showing total cost, personnel cost, material cost, solutions cost, drug cost and total Average direct cost, São Paulo, Brazil, 2017

\begin{tabular}{|c|c|c|c|c|c|c|}
\hline Observation & $\mathbf{n}$ & $\begin{array}{l}\text { Total } \\
\text { US\$ }^{*}\end{array}$ & $\begin{array}{l}\text { Average } \\
\text { US\$ }^{\ddagger}\end{array}$ & $\begin{array}{l}\text { SD§ } \\
\mathbf{U S \$}^{\ddagger}\end{array}$ & $\begin{array}{l}\text { Median } \\
\text { US\$ }^{\ddagger}\end{array}$ & $\begin{array}{c}\text { Minimum and Maximum } \\
\text { US\$ }^{\ddagger}\end{array}$ \\
\hline Nurse costs & 70 & $5,881.99$ & 84.03 & 32.49 & 74.58 & $26.23-193.13$ \\
\hline Technician/assistant costs & 68 & 527.11 & 7.75 & 5.70 & 6.50 & $0.05-29.44$ \\
\hline Nursing team $\mathrm{ADC}^{\dagger}$ & 70 & $6,409.15$ & 91.56 & 32.98 & 85.22 & $40.03-198.90$ \\
\hline Total material cost & 70 & $10,523.24$ & 150.33 & 75.11 & 111.73 & $74.86-422.29$ \\
\hline Solutions cost & 70 & 22.89 & 0.33 & 0.18 & 0.30 & $0.02-1.09$ \\
\hline Drug cost & 70 & 112.98 & 1.61 & 1.76 & 0.81 & $0.06-6.03$ \\
\hline Procedure total $\mathrm{ADC}^{\dagger}$ & 70 & $17,068.26$ & 243.83 & 84.47 & 243.05 & $123.15-530.71$ \\
\hline
\end{tabular}

Note: *PICC - Peripherally inserted central catheter; $† A D C$ - Average direct cost; $\neq C o n v e r s i o n ~ r a t e: ~ U S \$ 0.31 / R \$$, based on the August 31, 2016 quotation from Brazil's Central Bank; $§ S D$ - Standard deviation

Table 2 - Distribution of unsuccessful Peripherally inserted central catheter procedure observations with cost, personnel cost, material cost, solutions cost, medicines cost and Average direct cost total. São Paulo, Brazil, 2017

\begin{tabular}{|c|c|c|c|c|c|c|}
\hline Observation & $\mathbf{n}$ & $\begin{array}{l}\text { Total } \\
\text { US\$ }\end{array}$ & $\begin{array}{l}\text { Average } \\
\text { US\$ }^{\ddagger}\end{array}$ & $\begin{array}{l}\text { SD\$ } \\
\text { US\$ }\end{array}$ & $\begin{array}{l}\text { Median } \\
\text { US\$ }^{+}\end{array}$ & $\begin{array}{c}\text { Minimum and Maximum } \\
\text { US\$ }^{\ddagger}\end{array}$ \\
\hline Nurse costs & 31 & $2,076.55$ & 66.99 & 22.30 & 63.27 & $26.23-132.17$ \\
\hline Technician/assistant costs & 30 & 179.79 & 5.99 & 6.05 & 4.14 & $0.30-24.72$ \\
\hline Nursing team $\mathrm{ADC}^{\dagger}$ & 31 & $2,256.34$ & 72.79 & 23.42 & 66.17 & $26.93-137.72$ \\
\hline Total material cost & 31 & $3,496.88$ & 112.80 & 54.34 & 87.09 & $71.83-212.82$ \\
\hline Solutions cost & 31 & 10.52 & 0.34 & 0.16 & 0.29 & $0.11-0.87$ \\
\hline Drug cost & 31 & 54.91 & 1.77 & 1.74 & 0.69 & $0.06-5.17$ \\
\hline Procedure total $\mathrm{ADC}^{\dagger}$ & 31 & $5,818.32$ & 187.69 & 63.71 & 165.04 & $99.03-350.43$ \\
\hline
\end{tabular}

Note: *PICC - Peripherally inserted central catheter; $† A D C$ - Average direct cost; $\neq C o n v e r s i o n$ rate: US\$ 0.31/R\$, based on the August 31, 2016 quotation from Brazil's Central Bank; $§ S D$ - Standard deviation

The time spent by the nurse practitioner and other nursing professionals involved in venous punctures and catheter insertion ranged from two minutes to three hours and sixteen minutes, with a mean of $46(S D=39)$ and a median of 39 minutes. Considering the time spent only by nurses (where the nurse practitioner was the main contributor to total time), the variation was between two minutes and three hours, with a mean of $42(S D=36)$, median of 38 and mode of 40 minutes.

The catheter kits had the highest unit cost among items and were the most representative in the material cost composition, specially the 2 French (Fr) epicutaneous catheter + introducer two-way "kit" (unit cost - US\$208.82/35 units - \$7,308.70); the $2 \mathrm{Fr}$ epicutaneous catheter + introducer "kit" (unit cost - US\$ 74.09/27 units - US\$2,000.43), and the 3 Fr epicutaneous catheter + introducer "kit" (unit cost - US\$ 70.37/29 units - US\$ 2,040.73). In some procedures, up to two PICC were consumed, totaling 110 devices, 72 (65.50\%) made of silicone and 38 (34.50\%) made of polyurethane.

Concerning sedatives, Midazolam was the most consumed (US\$ 0.35/ampoule; 44 ampoules = US\$ 15.40); Dextroketamine had the highest unit value (US\$3.72/ampoule) and - despite only being the second most used drug - also the highest total cost (25 units = US\$ 93.00). As for antiseptic solutions, $0.5 \%$ chlorhexidine (US\$ 0.003/mL; $4711.85 \mathrm{~mL}=$ US\$ 14.11) had higher consumption than $2 \%$ chlorhexidine scrubbing solution (US\$ $0.003 / \mathrm{mL}$; $2789.90 \mathrm{~mL}=$ US\$ 8.37).

Total ADCs of successful and unsuccessful PICC procedures are shown in Tables 1 and 2. For both outcomes, material costs are the most significant component of cost, followed by personnel costs (mainly nurses' labor).

Considering that unsuccessful PICC procedures $(n=31)$ resulted in monetary loss for the hospital, total losses (US\$ 5,818.32) were absorbed into the cost of successful procedures. Thus, the total ADC of the procedure was US\$ 326.95 (SD = US\$ 84.47), with a US\$ 326.17 median, a minimum value of US\$ 206.27 , and a maximum value of US\$ 613.83

\section{DISCUSSION}

Characteristics of the patients submitted to PICC in the PNICU are similar to those described in the literature. A study performed at a private NICU revealed that the predominant clinical diagnoses among patients with this device were prematurity $(82.6 \%)$ and respiratory discomfort $(68.3 \%)^{(3)}$. In another NICU, the majority (86.5\%) of neonates submitted to PICC were diagnosed with prematurity, either by itself or in association with other diagnoses ${ }^{(1)}$.

The profile of the nurses participating in the study indicates that it is an experienced group, which explains why $34.77 \%$ of the total ADC of the PICC procedure corresponded to direct labor. In the studied hospital, the hiring process and the current career plan favors a lower turnover of professionals, increasing service time in the unit and, consequently, salary values.

In nursing professionals'ADC, especially when it comes to costs related to the direct labor of nurses, the average time to perform venipuncture and catheter insertion stood out, representing 
$29.92 \%$ (US\$23.58) of the total ADC of nurses (US\$ $78.80-100 \%$ ). It should be noted that, in spite of the fact that the nurse who executed the PICC is the professional who spends the most time in the procedure, this study also considered the participation of other nurses or technicians/assistants who have support roles necessary for making the procedure viable (sedation, patient repositioning, replacement of materials/solutions).

The time necessary for performing venipuncture and catheter insertion is variable, since different factors may interfere with the PICC implantation process. The mean time of venipuncture and catheter insertion presented here - 42 minutes $(S D=36)$ - is close to the average time presented by another research developed in the national setting (37.6 minutes) ${ }^{(19)}$. We believe that variations in the time taken to complete the procedure arise from difficulties experienced by the nurse practitioner, requiring support actions in order to finalize the insertion of the device without major risks to the neonatal/pediatric patient. In this sense, as expected, completion times for successful and unsuccessful PICC procedures were higher in the presence of difficulties (patient agitation, lack of blood vessel visibility, capillary fragility, multiple punctures, and inferior quality of materials), consequently leading to increased personnel costs.

It should be emphasized that the neonatal population presents very peculiar characteristics and requires efforts by the nursing team to guarantee a safe venous access, which may affect the survival and prognosis of newborns ${ }^{(3)}$. In the case of an unsuccessful PICC procedure, the patient will have to undergo new invasive procedures for the insertion of peripheral venous access or another central venous catheter. Further punctures for the insertion of a new PICC or another device causes pain, damages to the integrity of the skin, exposure to new risks of infections, and elevated consumption of sedatives/analgesics. Besides resulting in additional labor and material costs, it also implies intangible costs related to pain and suffering of the patient ${ }^{(6)}$.

Therefore, nurses performing venipunctures for PICC insertion need to have up-to-date knowledge, based on the best available evidence, on the different possibilities of analgesia adequate to the pediatric and neonatal population. A research ${ }^{(3)}$ developed in the NICU of a large private hospital in the city of São Paulo showed infrequent use of sedation and analgesia for the placement of PICC in neonates. Sedatives and opioid analgesics were the most used strategies; the study also indicated the need to verticalize current knowledge on the subject by carrying out new studies on the effectiveness of certain pharmacological and nonpharmacological analgesic strategies in the relief of neonatal pain related to the insertion of this device.

A 2013 prospective cohort study verified that the total cost of PICC insertion when performed by a radiologist physician averaged $£ 956.96$ ( $£ 94.27$ with labor), and $£ 242.28$ ( $£ 40.78$ with labor) when performed by nurses. Radiologist physicians took about 40 minutes to insert the device, while teams of nurses took about 63 minutes $(p<0.01)$, including about 10 minutes for room assembly. The shortest insertion time (18 minutes) occurred in the ICU, due to the procedure being executed at the bedside. Total cost of insertion by radiologists was $42 \%$ higher $(p<0.01)$. When adding the cost of room occupation, the cost of radiologists rose to $295 \%$ in comparison to nurses. The results showed that the greatest costs were for materials and radiologists; a potential saving of $£ 714.68$ per catheter insertion was estimated if nurses had inserted all devices. The study recommended the development of a vascular access team, led by nurses, but indicated the need for adequate funding and investments in training, management and accountability ${ }^{(5)}$.

We verified that the PICC insertion procedure in the studied PNICU had a high total ADC. However, it should be noted that, considering the risks implied in the insertion of a central venous catheter (CVC), the PICC procedure offers advantages in terms of patient safety and quality the provided care. Furthermore, its permanence time and durability, in comparison to prolonged use of peripheral venous accesses, reduces repetitive attempts to obtain vascular access, which consume resources and generate intangible costs to patients.

As previously mentioned, the total ADC of the PICC procedure was most significantly influenced by material costs - in line with studies on the direct costs of nursing expenses in the national context ${ }^{(4-13)}$ - followed by direct labor of nurses.

A qualitative, exploratory and descriptive study carried out in a public university hospital in the north of Paraná, and aiming to understand nurses' conceptions about cost management reports, found that participants were strictly focused on patient care (even those in managerial positions). According to 59 nurses, one nursing director, eight division chiefs, 25 section managers, and 25 care nurses, cost management was an administrative activity and care activities took all their available time. The authors identified a lack of academic training in cost management, which hindered participant's abilities to deal with the cost management report, or reinforced their resistance to do so. The nurses stated that they recognized the need for training to favor the daily use of this report and that such an instrument could help them optimize the use of resources ${ }^{(20)}$.

Since nurses are responsible for coordination, whether of the care team, the hospital unit or even materials' allocation, the pertinence of appropriating knowledge on health costs is latent, since these costs are increasing while resources remain fixed and limited ${ }^{(7)}$. Therefore, the understanding and analysis of procedure costs is an essential tool for managers and health professionals to contribute to the implementation of rationalizing measures, promoting the financial sustainability of healthcare organizations ${ }^{(13)}$.

Considering that additional venipunctures were one of the main complications mentioned by nurse practitioners, contributing to the high number of unsuccessful procedures, we argue in favor of establishing a protocol for the early indication of PICC as a strategy, in the short term, to increase the quality of care in intravenous therapy. Early indication, based on the patient's profile, associated with the awareness of the professionals regarding the relevance of preserving limbs for the future passage of PICC, would increase first-attempt successes, reducing both intangible costs to patients and average direct cost of the procedure. It would also allow for a catheter permanence time adequate to the prescribed therapy.

In the medium and long term, we recommend an investigation on the possibilities of creating a specialized PICC insertion team, duly trained to incorporate more advanced techniques - such as 
the use of ultrasound or other equipment to confirm the positioning of the device, by passive magnetic tracking or recording of electrical cardiac activity - and the adoption of the modified Seldinger technique, which would favor access to higher-caliber and more rectilinear veins, difficult to see with the naked eye or through superficial palpation. These strategies would reduce nurses' procedure execution time and, consequently, impact on the reduction of PICC direct costs. The feasibility of adopting the technologies available in the market would obviously require careful and thorough study, especially in public institutions whose financial resources are scarce, considering the necessary investments in human resources and the acquisition of equipments and devices that are already used by some Brazilian hospitals.

Health resources available for meeting assistance demands of varying complexities are limited and scarce. In the hospital area, critical care units have the highest material consumption, since they provide long care time, skilled professionals and sophisticated technology. Successful treatment of severe patients on intravenous therapy require central vascular devices for the infusion of specific drugs. Therefore, nursing professionals take on a singular role, by providing direct assistance to patients, inserting and handling one of the main types of catheters currently available in ICUs, the PICC, and also managing the materials used for its insertion.

\section{Limitations of this study}

The complexity of the actions that are part of the PICC insertion procedure made it impossible for their total time to be precisely identified.

\section{Contributions to the area of nursing, health or public policy}

This study, although constituting an initial approach on the subject, represents an advance in the knowledge about direct costs of PICC insertion, subsidizing the development of future researches that will be able to show, besides the financial aspects, the advantages and disadvantages of the adoption of different types of venous access.

It should be emphasized that, by effectively participating in the process of measuring, controlling and proposing strategies for the containment and minimization of procedure costs, the nurse can continuously improve the decision-making process, assisting in the adequate management of hospital costs, aiming at patient safety, quality of care and economic viability.

\section{CONCLUSION}

The development of this single-case study in the PNICU of a teaching hospital allowed the measurement of the total ADC of the PICC procedure as performed by nurses: US\$ 326.95 (SD = US\$ 84.47), ranging from US\$99.03 to US\$ 530.71, with a median of US\$ 326.17 .

Material costs, significantly increased by the prices of catheter kits (which presented the highest unit cost), followed by nurses direct labor costs, were the most expressive components of total ADC.

The measurement of the total ADC of the procedure gave financial visibility to consumption of materials, indicating possibilities of intervention able to increase allocation effectiveness.

\section{REFERENCES}

1. Cabral PFA, Rocha PK, Barbosa SFF, Sasso GTMD, Pires ROM. [Peripherally inserted central catheter at the Neonatal Intensive Care Unit]. Rev Eletr Enf [Internet]. 2013 [cited 2015 Oct 13];15(1):96-102. Available from: http://dx.doi.org/10.5216/ree.v15i1.15613 Portuguese.

2. Bittencourt RM, Gaiva MAM. [Early neonatal mortality related to clinical interventions]. Rev Bras Enferm [Internet]. 2014 [cited 2015 Oct 13];67(2):195-201. Available from: http://dx.doi.org/10.5935/0034-7167.20140025 Portuguese.

3. Costa P, Bueno M, Oliva CL, Castro TE, Camargo PP, Kimura AF. Analgesia and sedation during placement of peripherally inserted central catheters in neonates. Rev Esc Enferm USP. [Internet]. 2013 [cited 2015 Oct 13];47(4):801-7. Available from: http://dx.doi.org/10.1590/ S0080-623420130000400005

4. Zuliani LL, Jerico MC, Castro LC, Soler ZASG. [Costs and consumption of material resources in pediatric intensive and semi-intensive care units]. Rev Bras Enferm [Internet]. 2012 [cited 2015 Oct 13];65(6):969-76. Available from: http://dx.doi.org/10.1590/S003471672012000600013 Portuguese.

5. Walker G, Todd A. Nurse-led PICC insertion: is it cost effective? Br J Nurs [Internet]. 2013 [cited 2017 Mar 27];22(19):S9-15. Available from: http://dx.doi.org/10.12968/bjon.2013.22.Sup19.S9

6. Lima AFC, Castilho V, Fugulin FMT, Silva B, Ramin NS, Melo TO. Costs of most frequent nursing activities in highly dependent hospitalized patients. Rev Lat Am Enfermagem [Internet]. 2012 [cited 2017 Mar 27];20(5):880-7. Available from: http://dx.doi.org/10.1590/ S0104-11692012000500009

7. Lima AFC, Fugulin FMT, Castilho V, Nomura FH, Gaidzinski RR. [Contribution of electronic documentation of nursing for measurement of costs of health care body]. J Health Inform [Internet]. 2012[cited 2017 Feb 6];4:108-13. Available from: http://www.jhi-sbis.saude.ws/ojs-jhi/ index.php/jhi-sbis/article/view/239 Portuguese.

8. Nobrega CR, Lima AFC. Procedures' costs related to outpatient chemotherapy treatment of women suffering from breast cancer. Rev EsC Enferm USP [Internet]. 2014 [cited 2017 Feb 8];48(4):699-705. Available from: http://dx.doi.org/10.1590/S0080-623420140000400018

9. Castro LC, Castilho V. The cost of waste of consumable materials in a surgical center. Rev Latino-Am Enfermagem [Internet]. 2013 [cited 2017 Jan 14];21(6):1228-34. Available from: http://dx.doi.org/10.1590/0104-1169.2920.2358 
10. Gouvea AL, Lima AFC. Direct cost of connecting, maintaining and disconnecting patient-controlled analgesia pump. Rev Esc Enferm USP. [Internet]. 2014 [cited 2017 Jan 14];48(1):104-9. Available from: http://dx.doi.org/10.1590/S0080-623420140000100013

11. Ferreira GS, Aguiar MC, Lima AFC. [Cost of installing and turning off hemodialysis on patients with central venous catheters]. Rev Eletr Enf [Internet]. 2014 [cited 2017 Mar 27];16(4):704-9. Available from: http://dx.doi.org/10.5216/ree.v16i4.23044 Portuguese.

12. Tome MF, Lima AFC. Direct cost of reprocessing cotton-woven surgical drapes: a case study. Rev Esc Enferm USP [Internet]. 2015 [cited 2017 Feb 6];49(3):488-94. Available from: http://dx.doi.org/10.1590/S0080-623420150000300018

13. Lima AFC, Castilho V, Baptista CMC, Rogenski NMB, Rogenski KE. Direct cost of dressings for pressure ulcers in hospitalized patients. Rev Bras Enferm [Internet]. 2016 [cited 2017 Feb 6];69(2):269-75. Available from: http://dx.doi.org/10.1590/0034-7167.2016690212i

14. Dallora MELV, Forster AC. [The real importance of cost management in a teaching hospital: theoretical considerations]. Medicina (Ribeirao Preto. Online) [Internet]. 2012 [cited 2017 Mar 28];41(2):135-42. Available from: https://doi.org/10.11606/issn.2176-7262.v41i2p135-142 Portuguese.

15. Yin RK. Case study research: design and methods. 5th ed. London: SAGE; 2014. 350 p.

16. Martins E. Contabilidade de custos. 10 ed. São Paulo: Atlas; 2010. 312 p.

17. Lima AFC, Castilho V. Body mobilization for prevention of pressure ulcers: direct labor costs. Rev Bras Enferm [Internet]. 2015 [cited 2017 Feb 6];68(5):647-52. Available from: http://dx.doi.org/10.1590/0034-7167.2015680523i

18. Lima AFC. Direct cost of monitoring conventional hemodialysis conducted by nursing professionals. Rev Bras Enferm [Internet]. 2017 [cited 2017 Feb 6];70(2):357-63. Available from: http://dx.doi.org/10.1590/0034-7167-2016-0447

19. Costa P, Kimura AF, Brandon DH, Paiva ED, Camargo PP. The development of a risk score for unplanned removal of peripherally inserted central catheter in newborns. Rev Lat Am Enfermagem [Internet]. 2015 [cited 2015 Oct 13];23(3):475-82. Available from: http://dx.doi. org/10.1590/0104-1169.0491.2578

20. Oliveira WT, Rodrigues AVD, Haddad MCL, Vannuch MTO, Taldivo MA. Conceptions of nurses from a public university hospital regarding the cost management report. Rev Esc Enferm USP [Internet]. 2012 [cited 2015 Oct 13];46(5):1182-8. Available from: doi: 10.1590/ S0080-62342012000500021 